Wallace presided on the occasion, accompanied by Lady Wallace, and there was a large company present.

A TRAIN of Pullman carriages lighted by electricity has begun to run between London and Brighton.

THE Risikopf, on which the landslip occurred that recently overwhelmed the village of Elm in Switzerland, is being bombarded by heavy artillery in order that all the loose portions may be detached and thus prevent any future catastrophe.

EISENACH is to have an electric railway from the station to the Wartburg Castle, if the Royal permission can be obtained.

THE British Almanac and Companion for 1882 contains a summary of Science for I88I by Mr. J. F. Iselin. It is necessarily meagre, but Mr. Iselin has selected some of the leading points ; the geography is pretty full.

THE additions to the Zoological Society's Gardens during the past week include a Black-eared Marmoset (Hapale penicillata) from South-East Brazil, presented by Mrs. George Willins; a Tawny Eagle (Aquila navioides) from South Africa, presented by the Hon. - Southey; a Grey-breasted Parrakeet (Bolborhynchus monachus) from the Argentine Republic, a Black-headed Conure (Conurus nanday) from Paraguay, presented by Mr. J. Lloyd; two Talpacoti Ground Doves (Chamapelia talpacoti) from Para, a Plumbeous Snake (Oxyrrhopus plumbeus), two Taraguira Lizards (Taraguira smithi), a - Tree Frog (Hyla, sp. inc.) from Brazil, presented by Dr. A. Stradling, C.M.Z.S.; a Red-faced Spider Monkey (Ateles paniscus) from Guiana, three Red-billed Tree Ducks (Dendrocygna autumnalis) from South America, a Vinaceous Amazon (Chrysotis vinacea) from Brazil, a Redshank (Totanus calidris), two Dunlins (Tringa cinclus), two Razorbills (Alca torda), a Grey Plover (Squatarola helvetica), a Curlew (Numenius arquatus), British, purchased ; a Geoffroy's Dove (Peristera geoffroii), bred in the Gardens.

\section{THE ROYAL SOCIETY-ADDRESS OF THE PRESIDENT}

II.

$A$ FTER the Congress one of the most remarkable events during the present year has undoubtedly been the Electrical Exhibition in Paris. I do not of course purpose to describe it, as many of our Fellows visited it; and full descriptions have reached us through various channels. One point, however, must have struck those who examined any considerable number of the objects; and this I mention, not as in any way disparaging them, but rather as illustrating the stage to which electrical science has attained; namely, that while the assemblage of instruments and appliances was in every way remarkable, and while very great ingenuity and skill had been expended on their contrivance and construction, yet the amount of novelty in the principles involved was comparatively small. Of new combinations, improved methods, and adaptations in detail there was abundance. Some of them even removed former inventions from the category of curiosities to that of instruments for practical employment ; or enlarged their sphere of utility from that of the laboratory to that of every-day use. But such is the mass of fruitful matter which science has furnished to the mechanician and constructor, that we might almost wish, from the point of view of the latter, that they may have time to work out more fully than has yet been done, the results of science, before they are called upon to elaborate any fresh materials.

It is now proposed to repeat as far as may be this Exhibition at the Crystal Palace ; and the energy with which the proposal has been taken up, and the response with which it has met in many quarters, appear to justify sanguine expectations of its success, at all events from a practical and popular point of view. From the side of science it would doubtless have been far more interesting to look forward to a fresh exhibition, either here or elsewhere, of the progress of electricity after an interval of two

x Address of William Spottiswoode, D.C.L., LL.D., the president, deNovember 30, 188r. Continued from p. IIg. or three years. But there is nothing in the present undertaking to interfere with the more advanced project, if, after some such period as that indicated, circumstances should prove favourable. In the mean time it must be remembered that there are very many persons to whom the Paris Exhibition would have proved both interesting and instructive, but who, from one cause or another, were prevented visiting it. Besides this, there are not a few commercial, and even municipal, bodies desirous of adopting some of the modern applications of electricity, but who would be more ready to avail themselves of them after a personal inspection of the instruments and of their mode of action. From this point of view the exhibition may fairly be expected to give considerable impulse to the adoption of electrical appliances in fresh quarters.

But even over and above this practical aspect of the undertaking there may still have been, at the epoch of the Paris Exhibition, some results on the eve of achievement, some remedies for defects, sufficient to transform a doubtful into a certain issue, or even a failure into a success; some steps which may open out new questions, or serve as a departure for new investigations in the subject of electricity. If such should be the case, even science may derive substantial benefit from the proposed undertaking.

But the present year has been rendered generally remarkable, amongst other things, by the multiplicity of its congresses. A part from those which are concerned with subjects not coming under the head of " Natural Knowledge," there have been held the annual meetings of the British Association, and of the Iron and Steel Institute; the International Medical Congress, in London; the special Congresses on Electricity and on the Transit of Venus, in Paris (mentioned above); that on Geography in Venice; that on Geology in Bologna, and others. Among all these the International Medical Congress, which this year met in London, stands conspicuous. The work of that meeting showed that the study of medicine by the real workers is, in every part, even the most practical, pursued in a thoroughly scientific spirit; that facts are industriously collected, and patiently grouped and compared; and that conclusions are, if sometimes hastily drawn, yet very cautiously accepted. And there was ample evidence that help, whether in apparatus or in knowledge, is eagerly accepted from all the other sciences, whether their range be far from, or near to, the biological. In short, in the opinion of those best qualified to form a judgment, it is not too much to say that the whole tone of the proceedings of the Congress, though chiefly concerned with practical questions, was, in the best sense, even in the sense which the Royal Society would give to the term, scientific.

Several of the societies meeting annually, or at longer periods, have organisations which, during the intervals between two successive meetings, do useful work. But in all cases the meetings form the most prominent, if not the most important, feature of their life ; and, speakirg particularly of the meetings themselves, the question has more than once been raised whether they continue to justify the eftorts necessary to bring them about. It has been argued that, so many are the scientific periodicals in every civilised country, that all the papers of importance communicated to the meetings would under any circumstances be published in some place or other. Again, it has been urged that, so numerous are the centres of science, so many the means of communication both between places and between persons, that the necessity for these gatherings has, in the natural course of events, become superseded. The time which such meetings and the preparation for them involve, and the trouble which they entail on men already burdened with much work, have also been pleaded on the same side, and objections have been taken on the ground of the useless and irrelevant matter which is too apt to crop up on these occasions. These arguments are certainly not without weight; but there is still another side to the question. It is indeed quite probable that all the more important papers would be published even if the meetings never took place at all. But at these meetings there are usually a number of communications, many, but not all, of local origin, the production of which has been stimulated by the meeting itself; and a fair number of these may be reckoned on the side of gain. Again, it is true that the original idea of a parade or march-past of science, valuable enough when the provinces heard or saw little of science, has become less important now that provincial centres are to he found in almost every large town in the country. Nevertheless, the mere presence of some of the leading men stimulates dormant powers and encourages rising aspirations; and this perhaps all the more the 
case for the very reason that science and scientific names are no longer unknown. That most of the leading men have opportunities of meeting from time to time, and for scientific purposes, is certainly true; but that they should meet also on occasions when science is not too formal, is a thing which has its uses. And a concurrence of minds more numerous and more diversified than usual is sure to be fruitful of results. The whole advantage of these meetings, however, depends ultimately and fundamentally on the presence of a strong scientific element, which, from its own mere dignity and character, will repress all that is unworthy and will leaven the whole lump. Acting on this principle as a scientific duty, many good ncen have attended these meetings; and although they may have approached them with some degree of reluctance, few who during their attendance have taken their fair share in the proceedings, have come away without having derived a more favourable impression than that with which they entered.

Of such gatherings, the late meeting of the British Association at York was, if I may be permitted to express an opinion, a pattern and exemplar. And although it cannot be expected that in every year there will be so strong a muster as on the occasion of the fiftieth anniver:ary, yet all well-wishers of the Association must feel that it has entered upon its second half century with vigour and with dignity, and that it now remains only for its future supporters to maintain the high standard with which it has been handed down by those who have gone before.

It may be a matter of regret, although doubtless inevitable, that the same causes which have affected the social, the intellectual, the industrial, and the political life of our generation, and have made them other than what they were, should affect also our scientific life; but, as a matter of fact, if science is pursued more generally and more ardently than in former times, its pursuit is attended with more haste, more bustle, and more display than was wont to be the case. Apart from other reasons, the difficulty, already great and always rapidly increasing, of ascertaining what is new in natural science; the liability at any moment of being anticipated by others, constantly present to the minds of those to whom priority is of serious importance the desire to achieve something striking, either in principle or in mere illustration; all tend to disturb the even flow of scientific research. And it is perhaps not too much to say that an eagerness to outstrip others rather than to advance knowledge, and a struggle for relative rather than for absolute progress, are among the dangerous tendencies peculiar to the period in which we live. I do not, of course, for one moment mean to imply that this tendency universally prevails, for in Science, as well as in other pursuits, I believe that the best of the present would well stand comparison with the best of the past, and that there are nowadays men in the mid-stream of life who are as little affected by the eddies and back-waters with which they are surrounded as were the giants of former days. Nevertheless the danger is a real one, and is to be met with at every turn.

But the part of Cassandra is neither agreeable to the player nor welcome to the audience; nor is it indeed necessary that I should play it ; for, even although what I have said be true, it is still, I trust, not the whole truth. I have already spoken of noble exceptions; but although noble exceptions may go far to redeem the character of a nation or of a period, and example may have influences of which we hardly dream, yet for a general remedy I am more inclined to look to the natural course of events, and to what is often loosely spoken of as "things curing themselves." Such a cure may perhaps come about somehow on this wise. So multitudinous are the workers in every science, so numerous are the channels through which their discoveries are chronicled, that it is becoming every year more difficult for even the learned and the well-read to say what is and what is not new, or what has not been published before. Claims for novelty must, therefore, as time goes on, be put forward with greater and greater diffidence. The only originality that can be safely claimed will be originality on the part of the investigator; and the question of absolute priority must be left to the verdict of time and of that sifting process by which ultimately all discoveries will find their proper places in the Temple of Science.

When this stage is reached, and we are even now approaching it, the fever of to-day may in a great measure subside and give place to a more tempered, although still fervent glow of aspiration. The eagerness and haste to which we have become almost accustomed may be chastened by the reflection that questions of priority are not to be settled by a mere stroke of the pen, and that in the comparison of rival claims the question of the quality of work will undoubtedly arise and become interwoven with that of priority. And so in the end it may come to pass that a half understood experiment or a hastily drawn conclusion may avail less than ever for establishing a reputation, and that, even for the purpose of winning the race, it may be worth while to spend sufficient time in laying sure foundations and in building a superstructure commensurate with that on which it stands and well-proportioned in all its parts.

The transference of the Natural History Collections of the British Museum to the new building at South Kensington is still in progress. It is hoped that the building for the specimens preserved in spirits, as well as the fittings for the zoological department, will be so far completed as to allow of the moving of that department during the autumn of 1882 . The lighting of the reading-room by Siemens' lamps is so far satisfactory, that it has been decided to keep that room open in future until $8 \mathrm{p.m}$., instead of $7 \mathrm{p} . \mathrm{m}$. This change, it is hoped, will prove to be of substantial service to a large class of readers.

The Institution founded in $185 \mathrm{I}$, under the title of the Go* vernment School of Mines and Metropolitan School of Science applied to Mining and the Arts, for the instruction of students in those branches of science which are indispensable to the Miner, the Metallurgist, the Geologist, and the Industrial Chemist, has this year been organised afresh, and, under its new title of the Normal School of Science and Royal School of Mines, adds to its former functions the training of teachers for the Elementary Science Classes under the Science and Art Department, the multiplication of which, in recent years, is a significant indication of the rapid spread of scientific instruction throughout the country.

The accommodation requisite for practical teaching being inadequate in all cases and totally wanting in respect of many of the classes, in the Museum of Practical Geology in Jermyn Street, and in the Royal College of Chemistry in Oxford Street, all the instruction, except that in Mining, has been transferred to the Science Schools at South Kensington. The staff of professors and lecturers has been increased, and provision has been made for the teaching of various important subjects, such as Mathematics, Drawing, Botany, and the Principles of Agriculture, which were either omitted, or insufficiently represented, in the original programme of the school.

Under its new organisation the Normal School of Science and Royal School of Mines will not merely supply from among its associates persons highly qualified to apply the principles of science to the Mining, Metallurgical, Chemical, and Agricultural industries of the country, and properly trained science teachers; but, through the exhibitions attached to the yearly examinations of the Science and Art Department, it will place within reach of promising young students in all parts of the country, whose means do not enable them to obtain the benefits of a University education, such a training as will enable them to turn their natural abilities to account for the advancement of science and the improvement of its applications to industry. Under the latter point of view, the instruction given in the Normal School of Science will lead up to the special technical training of the Central Institute of the Guilds of the City of London.

Under the auspices of the City and Guilds of London Institute, further progress has been made during the past year in the promotion of Technical Education. It will be remembered that the work at present undertaken by the Institute embraces the establishment of a Technical Science School in Finsbury, a Technical Art School in Kennington, a Central Institution or Higher Technical College in Kensington, the subsidising of existing institutions, affording facilities for Technical Instruction and the encouragement of existing classes in the manufacturing centres by the grants paid to teachers on the results of the Technological Examinations.

In May last the foundation stone of the Finsbury College was laid by H.R.H. Prince Leopold, and the new building, which will afford accommodation for the teaching of applied Chemistry, Physics, and Mechanics, will be finished early in next year. Notwithstanding the inadequacy of the present temporary accommodation, large numbers of students have availed themselves of the instruction afforded. The principles of Electric Lighting, and Transmission of Power, the making of Electrical Instruments, Coal Tar, and Spirit Distilling have been the subjects that have beea chiefly studied during the past session.

Since October the classes that were previously conducted by the Artisans' Institute have been transferred to the Finsbury College. 
The Institute has under its consideration the establisbment of a School for Applied Art in connection with the Finsbury College. Acting on the general principle that every Technical School of this kind ought to provide, in addition to the general course of instruction, as applicable to different industrie, special courses applicable to the staple industry of the district, the Council of the Institute are contemplating the establishment of classes in the Finsbury College adapted to the educational requirements of those engaged in Cabinet-making. With this object it will be necessary to attach a Scbool of Design to the Collexe.

The influx of pupils to the studios in Kennington have indaced the Council to vote a sum of money for the extension of the building in which the Art School of this district is conducted. These new buildings are nearly completed, and will afford accommodation for Classes in Modelling, Design, and Wood Engraving.

The building of the central institution, which is to be in the first place a school for the training of technical teachers, has been commenced. The first stone was set in July last by H.R.II. the Prince of Wales, who is now the President of the Institute. The plans of this building show accommodation for the teaching of the different branches of Physics in their application to various industries, of Chemistry as applied to trade purposes, and of Mathematics and Mechanics in their application to Engineering. A gord engineering school, coutaining workshops, well supplied with rachinery and collections of mechanical instruments and morele, such as exist in numerous Continental cities, scems likely to be obtained for London on the completion of this building.

This Institute bas done much towards the encouragement of technical instruction in provincial towns, where it is most needed, by its system of annual examinations. In the examination held in May last, 1563 candidates presented themselves, in twenty eight subjects, from 115 centres, and of these 895 passed. A close connection is being established betwcen the several tech. nical schools which are being $n$ )w opened in Lancashire and Yorkshire, and the City and Guilds of London Institute. The demands made uron the Institute by Chambers of Commerce in different parts of England satisfactorily indicate the usefulness of this part of the Institute's work.

The programme of Technological Exaninations for $1881-82$, just issued, shows thirty-two subjects in which examinations may be held, some of which are divided into four or five branches, so that they may be better adapted to individual industries. Whilst attention has in this way been given to the details of different trades, the attempt has been made to secure from candidates passing the Institu'e's examinations a general knowledye of the principles of their subject and of the relation of closely connected industries $\mathrm{u}$ ith one another.

In order to secure in future efficient teachers, the Council of the Institute have determined af ter March next not to register as teachers any persons except those who have pas:cd the In titute's IIonours Examination, or such as already posiess special or distinct qualifications.

The interest which the sulject of technical education is beginning to arouse has led to the appointment by the Crown of a Commission to inquire into the education of the induitrial cla-ses in England and in other countries; and the City and Guilds of London Institute is represented on this Commission by Prof. Roseoc, who, as President of the Chemical Society, occupies a seat on the Executive Committee, and also by Mr. I'hilip Magmus, its director and secretary. The Commi-si-ners are at present engaged in making a tour of inspection in France, a section of them having already visited some of the principal technical schools and factories in the north of Italy.

In Metcorological Science the preseut year has been marked by the publication of an important work ("Dic Temperatur Verhältnisse des russischen Reichs," St. Petersburg, 1880), by Prof. Wild of St. Petersburg, on the Temperature of the Russian Empire, embodying, in charts and tables, a great amount of information, hitherto either inaccessible or existing only in scattered memoirs, relating to the incteor ul. gy of the vast tracts of Northern Asia. As an interesting particular result it may be nuentioned that Prof. Wild has transferred the "Siberian pole of cold in winter" from the neighbourhood of Jakutsk to a p sint somewhat further north, lying on the Arctic Circle in (aboui) E. longitude $125^{\circ}$. At this centre of maximum cold, round which the isotherms lie in fairly regular ovals, the mean temperature in January sinks as low as $-54^{\circ} \mathrm{F}$., the mean temperature at Jahutsk being $\mathrm{II}^{\circ}$ hisher. In close relation to the phenomena exhibited by these charts, Prof. Wild, in St. Petersburg, has been led to stuciy the connection between areas of permanent high or low mean pressure on the one hand, and areas of permanent high or low mean temperature on the other; and he has found this connection to be of the same kind as that known to exist in the case of the shifting areas of high or low pressure, and high or low temperature, which determine the changes of weather. M. Léon Teisserenc de Bort, in Paris, has also investigated the same subject.

The Meteorological Office has completed during the year two works of some interest, which are now ready for immediate publication. The first consists of tables of the Rainfall of the British Isbes, prepared at the request of the Council of the Office by Mr. G. J. Symons, F.R.S. These tables include the monthly results recorded at 367 stations in the United Kingdom, being all those for which it was possible to obtain series of observations maintained continuously during the last fiftecn years. The second is a volume of charts (with an introduction and explanations) illustrating the metenrology of an ocean district specially imrortant to seamen-that adjacent to the Cape of Good Hope. Some points of novelty are presented by the charts. For example, a new form of "wind-rose," invented by Mr. F. Galton, F.R.S., has been employed, which offers some theoretical advantages over those previously in use, being intended to represent, with gematrical precision, the probability (deduced from the observation:) that, in a particular place and at a particular scason, a "Iind blowing betwee 1 any two given points of the compass will be experienced. Again, for the first time in marine meterrology, the wind observations have been "wcighted" with the view of neutralising the tendency to over-estimate the frequency of adverse winds, which has been found to affect meteor(slogical charts injuriously. The work brings into clear relief the most interesting physical feature of the district-one indeed alrearly uell known-the intermingling of hot and cold water, brought by the Agulhas and the South Polar currents respectively, and supplies strong evidence for the belief that this intermingling has a large share in producing the atmospheric dis. turbances so common in the region in which it occurs.

In my Address to the Society in 1879 , I stated that an International Conference of a semi-official character had been held, with the view of establishing for one complete year a circle of meteorological observations round the Arctic regions of the globe. Notwithstanding the lamented death of Lieut. Wey. precht, the gallant young discoverer of Franz-Josef Land, by whom the proposal bad been originated, it would seem that the efforts of the Conference are likely to be crosned with snccess. The following stations have alreedy been undertaken by different Governments:-l'oint Barrow and Lady Franklin's Bay in Smith's Sound, by the United States; West Greenland, by Denmark; Jan Mayen, by Autria; Mossel Bay and Spitzbergen, hy sweden; Bossekop, by Norway; Nova Zembla, hy Hollund t the Moutbs of the Lena, by Russia. The Conference has also been led to bope that the Canadian Government may reinstitute observations at Fort Simpson, and that the Government of France may organise a simultaneous meteorological expedition to 'Terra del Fuego. It is arranged that the observa. tions should begin as soon as possible after August I, I88I, and should continue to September 1,1883 .

In astronomy $\mathrm{Mr}$. Gill has completed his discussion of the extensive series of heliometer measures of the parallax of Mars, which he made at Ascension in 1877 , and has deduced the value $8^{\prime \prime} \cdot 78$ for the solar parallax, corresponding to a mean distance of $93,080,000$ wiles from the earth to the suv. A value of the solar parallax has also been derived by Mr. D. P. Todd, from the Amerivan photographs of the transit of Vemus, 1874 . The result for the parallax is $8^{\prime \prime} \cdot 883$, corresponding to a mean, distance of $92,028,000$ miles.

A valuable contribution towards the determination of the moon's physical libration has been made by Dr. Hartwig. From a series of forty-two measures made with the Strassburg heliometer he derives values for the physical libration and for the inclination of the moon's axis, substantially confirming the results found by Wichmann, and recently by Prof. Pritchard.

An addition to the small list of stars which have been found to have a measurable parallax has been made by Dr. Ball. Ile finds that the star Groombridge 1618 , which is remarkable for its lange proper motion, has a parallax of about one-third of a second, so that it is to be considered one of the sun's nearest neighbours. Dr. Ball has also re-determined the parallax of the 
double star 6r Cygni, his result being $\mathrm{o}^{\prime \prime} \cdot 468$, which agrees more nearly with Struve's value than with Bessel's.

The Cape catalogue of upwards of 12,000 stars is the outcome of Mr. Stone's labours during nine years, as Her Majesty's Astronomer at the Cape, and is the most important catalogue of stars which has yet been formed in the southern hemisphere. Another important contribution to stellar astronomy has been made by Prof. Newcomb, who has recently prepared a catalogue of the places of nearly I I00 standard stars compiled from the best authorities.

In connection with his photometric researches Prof. Pickering has discussed the causes of the variability of stars of short period. Taking the various hypotheses which have been proposed, he finds that for Algol and stars of that type the hypothesis of an eclipsing satellite or cloud of meteors revolving round the star is the only one which satisfies the observed phenomena. In the case of $\beta$ Lyræ and similar variables the fluctuations of light would be explained as due to rotation round the axis, the two hemispheres being of unequal brightness and the form more or less elongated. Prof. Pickering has very carefully investigated the conditions in each individual case, and has brought together the most important facts bearing on the subject. It may be mentioned that on Prof. Pickering's initiative a committee of American astronomers has been formed to co-operate with European astronomers in selecting a series of stars to serve as standards of stellar magnitude.

The present year has been remarkable for the appearance of two bright comets simultaneously visible to the naked eye. The first comet was first seen in the southern hemisphere before it perihelion passage, and burst upon our view in its fu!l splendour soon after perihelion. The most important point in connection with this comet was that photographs of its spectrum were obtained by several physicists, and in particular by Dr. Huggins, who found on his photographs two strong bright lines in the ultra-violet corresponding to a group in the spectra of compounds of carbon, and also a group of lines between $\mathrm{G}$ and $h$ agreeing in position with another carbon-band. The photographs also showed a continuous spectrum extending from $\mathrm{F}$ to some distance beyond $\mathrm{H}$, on which the dark Fraunhofer lines were seen-an indication that part of the light from comets is reflected solar light.

In the visible portion the continuous spectrum was so bright when the comet was first seen after perihelion that it almost obliterated the ordinary cometary bands. These, however, became afierwards very conspicuous, and five bands were noted which were found to coincide sensibly with the carbon band as given by the flame of the Bunsen burner. On the brightest band, three bright lines corresponding to three lines in the carbon band were seen by several observers at Princeton, U.S. These observations show conclusively that the spectrum of this comet is identical with the frst spectrum of carbon, and not with the second.

In the telescope this comet showed striking changes from day to day, and even, according to some observers, from hour to hour, and the head was remarkable for its unsymmetrical appearance. Another point of interest is that the orbit presents a remarkable resemblance to that of the great comet of 1807 . As, however, the period of this latter was found by Bessel to be $\mathbf{r} 540$ years, the question arises again, as in the case of the comets of 1843 and 1880 , whether there are not two comets travelling along the same path.

The second bright comet was first discovered with the telescope, and gradually increased in brightness till it became visible to the naked eye, though by no means so interesting an object as the preceding comet. Besides these two bright comets, several telescopic comets have been discovered, raising the total for this year to eight. The last but one of these has proved to be a periodic comet, revolving in the short period of about eight years. It was discovered by an Englishman, Mr. Denning, being the first instance of such a discovery in this country for many years.

The Copley Medal has been awarded to Prof. Karl Adolph Wurtz, For. Mem. R.S. Prof. Wurtz has, for many years past, been one of the most distinguished leaders of the progress of chemistry, and is now the most eminent of active French chemists. The younger generation of French chemists were, for the most part, his pupils. His writings have been the medium by which most of the knowledge of the more modern theories of chemistry has been disseminated in France. His discoveries have been fruitful of the greatest results, not merely in the way of enriching the science with a knowledge of many previously unknown compounds and classes of compounds, but more especially in extending and improving our knowledge of the laws of chemical combination.

It was he who first discovered compound ammonias contain. ing alcohol-radicals in the place of hydrogen-a family of compounds which has since acquired enormous development. It was he who first made those remarkable alcohols called glycols, and thus gave the key to the explanation of glycerine, erythrite, mannite, and the sugars. Many other diseoveries of his might be quoted; but those who know the influence which these two have exercised on the proyress of chemistry can feel no doubt that the author of them is deserving of the highest scientific honour.

One Royal Medal has been awarded to Mr. Francis Maitland Balfour, F.R.S. Mr. F. M. Balfour's investigations in embryology and comparative anatomy have placed him, thus early it life, in the front rank of original workers in these branches of science. His "Monograph upon the Development of Elasmobranch Fishes," published in 1878 , embodies the results of several years' labour, by which quite a new light has been thrown upon the development of several important organs in the Vertebrata, and notably of the genito-urinary and nervous systems. More recently Mr. Balfour has published a most im portant work on "Comparative Embryology" in two large and fully illustrated volumes, which stands alone in biological literature, not only as an admirable and exhaustive summary of the present state of knowledge respecting the development of animals in general, but by reason of the vast amount and the varied character of the original researches which are incorporated in its pages.

A second Royal Medal has been awarded to the Rev. John Hewitt Jellett, F.R.S., Provast of Trinity College, Dublin. Dr. Jellett is the author of various papers on pure and applied mathematics; but the award is more directly connected with his invention of the analyser known by his name, and for the elaborate optico-chemical researches which he has made with it.

This analyser was introduced by its inventor into the instrument by which he has carried on his researches on the state of combination of mixed solutions, as evidenced by the changes in their power of rotating the plane of polarisation consequent upon a change in the proportion of the active ingredients which enter into the solution. This is a problem towards the solution of which ordinary chemical methods can contribute but little. A single instance will suffice to give an idea of the nature of the results. It is known that quinine forms with many acids two series of salts, one having twice the quantity of acid of the other for the same quantity of base, while with other acids only the less acid salt has been obtained; so that the ordinary chemical methods fail to give evidence of the existence of the more acid salt. Now, by examining the rotatory power of a solution of a given quantily of base with different doses of acid, Dr. Jellett was able to obtain evidence of the existence of two, and but two, salts of the base, no matter whether the acid were or were not one which yields two crystallisable salts. A slight deviation in the amount of rotation when the more acid salt began to be formed in tolerable quantity, from what it ought to have been, on the supposition that the whole of the acid introduced was combined with the quinine, was naturally attributed to a slight partition of the acid between the base and the solvent, regarded as a feeble base; but the smallness of the deviation indicated that a solution of the more acid salt mainly existed as such, and that it was not, as some had supposed, decomposed into free acid and the less acid salt.

The Davy Medal has been awarded to Prof. Adolf Baeyer. Prof. Baeyer was already known as the author of many masterly researches in organic chemistry, among which those on uric acid and on.metallic acid deserve special mention, before his latest and most remarlsable discovery. The process for the artificial formation and manufacture of indigo is the result of long-continted efforts, directed by singularly clear and accurate views of the order and mode of combination of its constituent elements, and of the conditions requisite for obtaining reactions indicated by theory.

The work of the Royal Commission on Accidents in Mines during the past year has been of such great interest, both from a scientific and from a practical point of view, that I venture to note at length some notes upon it, furnished to me by our Fellow, Mr. Warington Smyth, the Chairman.

A preliminary report was presented before the end of the 
Session 1881, drawing attention, under the chief heads of the subject, to the facts and opinions elicited from the examination of a large number of competent witnesses.

Experimental inquiries, which will be the subject of a further report, have been instituted for the purposes of testing the various safety-lamps in use, as well as the numerous modifica. tions recently proposed, and of determining the effect of coaldust in causing or aggravating explosions. From time to time also experiments have been made with a view to substitute, in the breaking down of coal, some other means for the gunpowder shots which have so often, by their flame, caused the ignition of fire-damp.

The presence of a powerful "blower" of natural gas at the Garswood Hall Colliery, near Wigan, with the facilities offered by the proprietors, induced the Commission to erect suitable apparatus for a long series of these trials, and now that it appears desirable to compare the results with what may be obtained in another district and with a differently constituted fire-damp the whole of the apparatus is in course of erection at a colliery in the Rhondda Valley, where a very permanent "blower" offers similar advantages.

In the course of the lamp experiments it came out very clearly, in confirmation of statements before made, that the greatly augmented ventilation in our larger modern collieries has put an end to the fancied security of the simple Davy and Clanny lamps. Their use in fact, unless they be protected by some farther contrivance, is attended with the most imminent risk when the velocity of a current liable to be rendered explosive, exceeds six feet a second. A high degree of importance thus attaches to the comparative trials of lamps in which the flame is sufficiently shielded against the impinging stream of air, and those which have the property when immersed in an explosive mixture, of rapidly quenching both the flame of the wick and of the burning fire-damp.

The terrible disaster which occurred in September, 1880, at the Seaham Colliery, drew more anxious attention than ever to the question of the part played by coal-dust, and a special reference having been made by the Secretary of State for the Home Department to Prof. Abel, C.B., the experiments at Garswood Hall were largely extended. Some of the results were very remarkable; the proportion of fire-damp present with the air may be so small as to elude detection by the ordinary test of the carefully watched flame in the safety-lamp, and yet the presence of dust in suspension will cause rapid ignition, or even explosion, in a degree varying with the proportion of gas and the velocity of the current. Dust was employed from different parts of the works of several collieries where it was suspected that this agent had borne a serious part in intensifying and spreading explosions; and it was found that some of the varieties were far more sensitive than others. Certain kinds of dust, in themselves perfectly non-combustible, were similarly tested, and proved to have an analogous effect in promoting explosion, even when the percentage of gas was exceedingly small.

It is obvious from these facts that under certain conditions it is very important that a satisfactory indicator of minute proportions of fire-damp should be employed ; and the further experiments proposed to be carried out by the Commission will include a particular inquiry into this subject.

The question of the feasibility of the introduction of the electric light into the workings of a colliery has been partially solved. The Stanton Coal and Iron Company were induced by the Commission to make a trial of Mr. Swan's lamps in their Pleasley Colliery, near Mansfield. Not only the inset and main road, but some of the "long-wall" faces of work, were brilliantly lighted in this manner. A second experiment of the same kind has been carried out at the Earnoch Colliery, near Hamilton.

The use and abuse of explosives in mining operations have in the last few years formed a subject of much inquiry, especially with reference to the firing of shots in coal-seams liable to be invaded by fire-damp. A return to mere wedging in all cases, as proposed by some officials, would be to ignore the advance of science as well as the necessities' caused by competition; and the Commission hopes by further examination, and especially by practical trials, to contribute useful information to the solution of a difficult but important question.

Among the applications of scientific apparatus the employment of the ingenious protected lime-light lamp, and of the portable breathing arrangement of Mr. Fleuss, during the operations for re-opening of parts of the Seaham Colliery, deserves special notice.

\section{UNIVERSITY AND EDUCATIONAL INTELLIGENCE}

CAMbridge. -Messrs. W. M. Hicks and W. W. R. Ball are appointed Moderators in the Mathematical Tripos for the year beginning next May. The Senior Wranglership will in future be adjudged in June.

The Examiners for the Natural Sciences Tripos in 1882 are Lord Rayleigh, Prof. W. J. Lewis, Prof. Morison Watson (Owens College), Drs. Gaskell, R. D. Roberts, and Vines, Mr. A. G. Vernon Harcourt (Oxford), and Prof. A. M. Marshall (Owens College).

Mr. R. T. Glazebraok, Demonstrator of Experimental Physics, is approved as a Teacher of Physics, and Mr. A. S. Lea, Lecturer at Caius College, is approved as a Teacher of Physiology for the purpose of Medical Studies.

Clare College offers a Natural Science Scholarship, examination March 28 ; subjects : Chemistry, Chemical Physics, Botany, Geology. Candidates must give notice a fortnight previously to the tutor.

GLASGOW.-The matriculations for the present session number 2316, distributed among the various Faculties as follows, viz. :In Aits 1327 , in Medicine 624, in Law 211 , in Theology 100 , in Arts and Medicine 25, in Arts and Law 9, in Arts and Theology 20. The total number of matriculations last session was 2304, distributed as follows :- In Arts 1406, in Medicine 563, in Law I89, in Theology 85, in Arts and Medicine 29, in Arts and Law 18, in Arts and Theology, 14.

\section{SCIENTIFIC SERIALS}

Fournal of the Franklin Institute, October.-Experiments on the strength of wrought iron and steel at high temperatures, by Mr. Roelker.-On the proper method of expansion of steam and regulation of the engine, by Prof. Thurston.-On the last experiment with the Perkins machinery of the anthracite, by Ch. Eng. Isherwood. - Radio-dynamic facts, by Dr. Chase.Universal energy of light, by the same.

Annalen der Physik und Chemie, No. Io.-Photometric researches on absorption of light in isotropic and anisotropic media, by C. Pulfrich.- - On the vapour-tension of mixed liquids (continued), by D. Konowalow.-On the heat of formation of water, by A. Schuller,-On the heat-conductivity of gases and its connection with temperature, by L. Graetz.-Past observations on the expansion of water by heat, by P. Volkmann.-On the theoretical determination of vapour-pressure and volumes of vapour and liquid, by $R$. Clausius.-On heat-conduction in a system of cylinders, and on the experimental determination of the conductivity of water, by H. Lorberg.-On magnetic reaction, by F. Auerbach. - Application of the balance to the problem of gravitation, by Ph. v. Jolly.-On the spectra of hydrogen and acetylene, by A. Wüllner.-Some remarks on Herr Wesendonck's experiments on spectra of carbon compounds, by the same. - The minimum of deflection of a ray of light in a prism, by K. H. Schellbach. - Contribution to history of natural sciences among the Arabians, by E. Wiedemann.

La Natura, Nos. 21 and 22, November.-The Italian section at the Paris Electrical Exhibition, by R. Ferrini.-Thermal radiation of the sun, \&c. (continued), by C. Cattaneo.-On the origin of electricity of storm-clouds and of the air, and on electricity in general, by F. G. Nachs.

\section{SOCIETIES AND ACADEMIES LONDON}

Royal Society, November 17.- "Researches on Chemical Equivalence." By Edmund J. Mills, D.Sc., F.R.S., and J. H. Bicket. Part IV. : Manganous and Nickelous Sulphates.

The authors have examined the precipitability and precipita. tion of manganous and nickelous sulphates, alone or commixed, by means of sodic carbonate. The chemical events they describe are represented in a series of four hyperbolas, whose equations are given in the memoir. They sum up their results as follows :-(I) Precipitability is a linear function of mass; (2) when the commixed sulpbates are precipitated by sodic carbonate, equal weights of them are equally precipitable, the attraction of one of them for the reagent being the inverse of that of the other ; (3) when the sulphates are separately precipitated by the same reagent, they are equally precipitable, and do 